\title{
Status of LBNF Beam
}

Keith Gollwitzer

Fermi National Accelerator Laboratory

NuFact 2021: The 22nd International Workshop on Neutrinos from Accelerators 10 September 2021 


\section{Outline}

- Requirements

- Primary Beam

- Target Complex

- Decay Volume Structure

- Absorber Complex

- Instrumentation \& Monitoring

- Civil Facilities 


\section{LBNF Beamline Requirements \& Optimization of Parameters}

- Design for initial delivery of 1.2 MW beam power; upgradeable to $2.4 \mathrm{MW}$.

- Proton beam energy between $60 \mathrm{GeV}$ and $120 \mathrm{GeV}$

- Pulse length of $\sim 10 \mu \mathrm{sec}$

- Proton beam size on target tunable $1.0-4.0 \mathrm{~mm}$ rms

- Beam Optimization was performed to maximize DUNE physics (with some engineering constraints)

- Three focusing horn system (geometry and spacing part of optimization)

- Target inserted in first horn

- Magnetic field generated by a 300,000 A pulse (half-sine wave of $800 \mu \mathrm{sec}$; beam at flattop)

- Target to be cylindrically symmetric

- Graphite material

- Length of target desired to be four interaction lengths 


\section{Primary Beam}

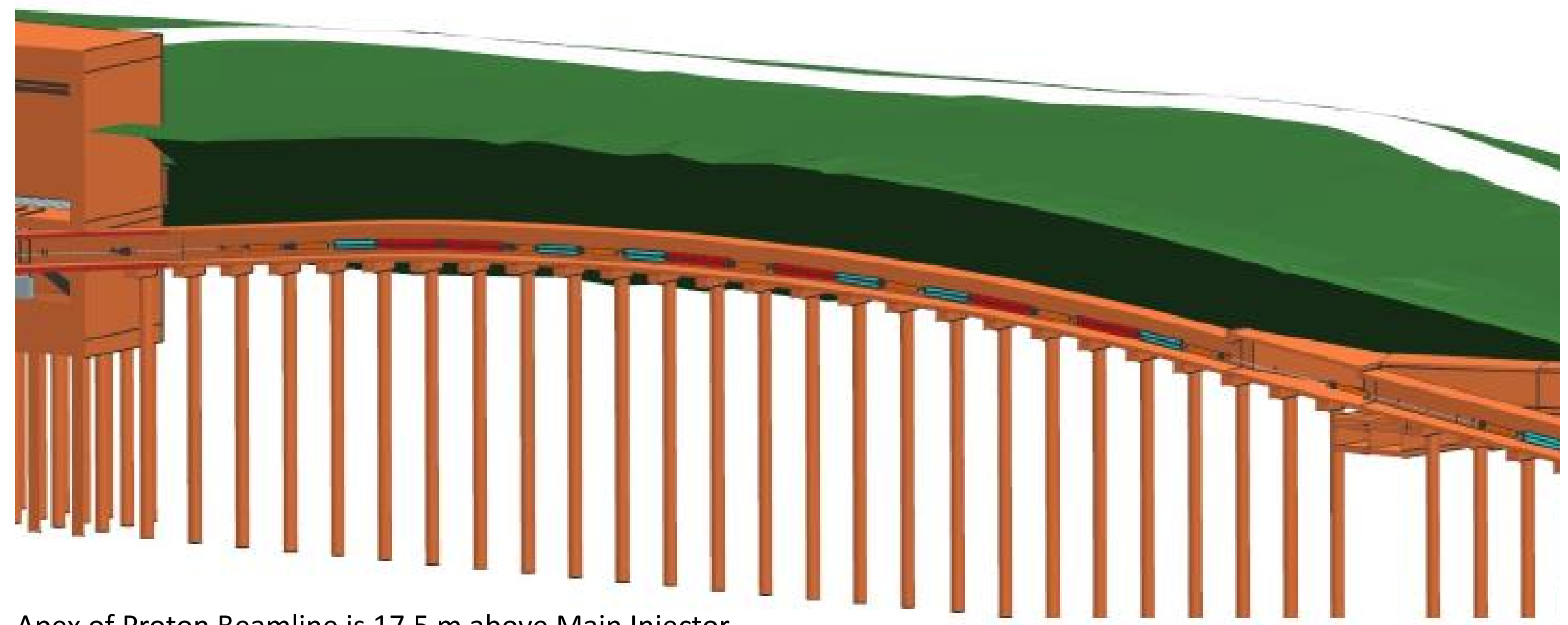

Apex of Proton Beamline is $17.5 \mathrm{~m}$ above Main Injector

From Apex to target, beam drops $6 \mathrm{~m} \&$ is at correct downward angle (101 milliradian) directed at DUNE detectors 


\section{Primary Beam}

Magnet Installation

Tunnel Junction
Main magnets

25 dipoles

21 quads

23 correctors

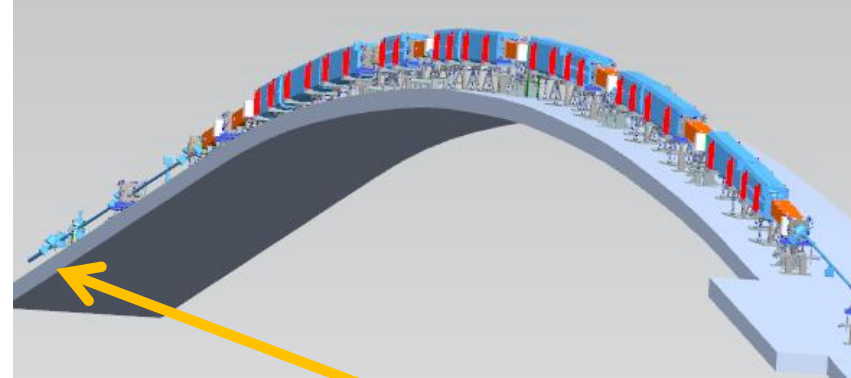

DS End: Primary

Beam Window

Maximum 140

Main Injector

Wall Penetration

milliradian slope
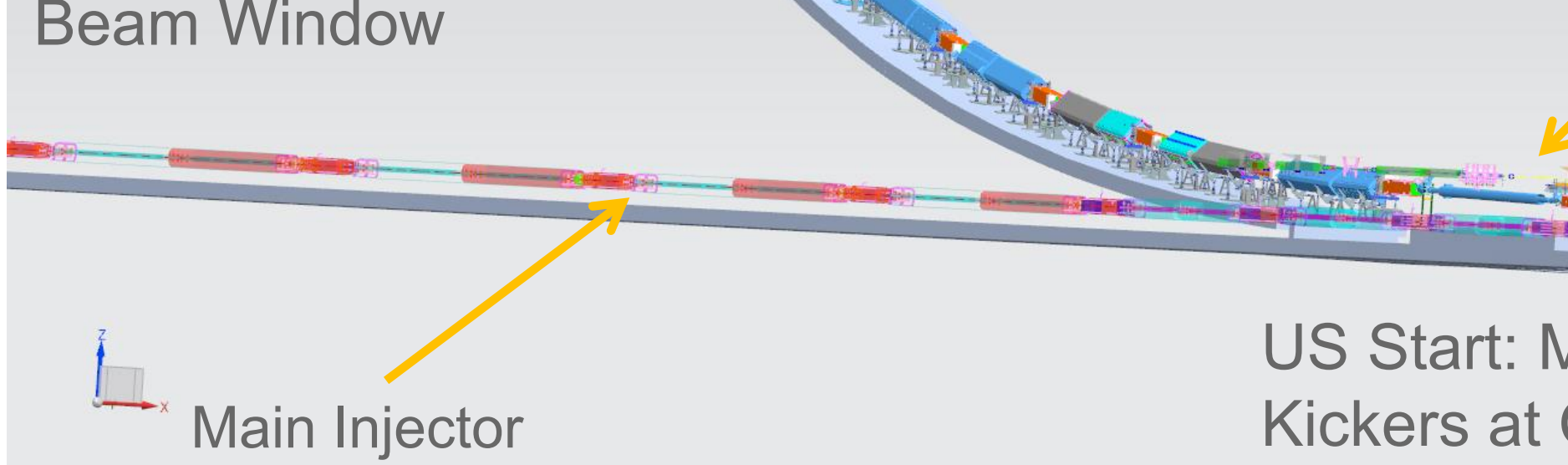

US Start: MI

Kickers at Q100

\section{Lambertsons}

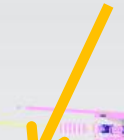

mins 16 now 


\section{International Partners for Magnets}

- Dipoles and Quads

- BARC of India

- Based upon previous Fermilab designs

- Prototype fabrication about to begin

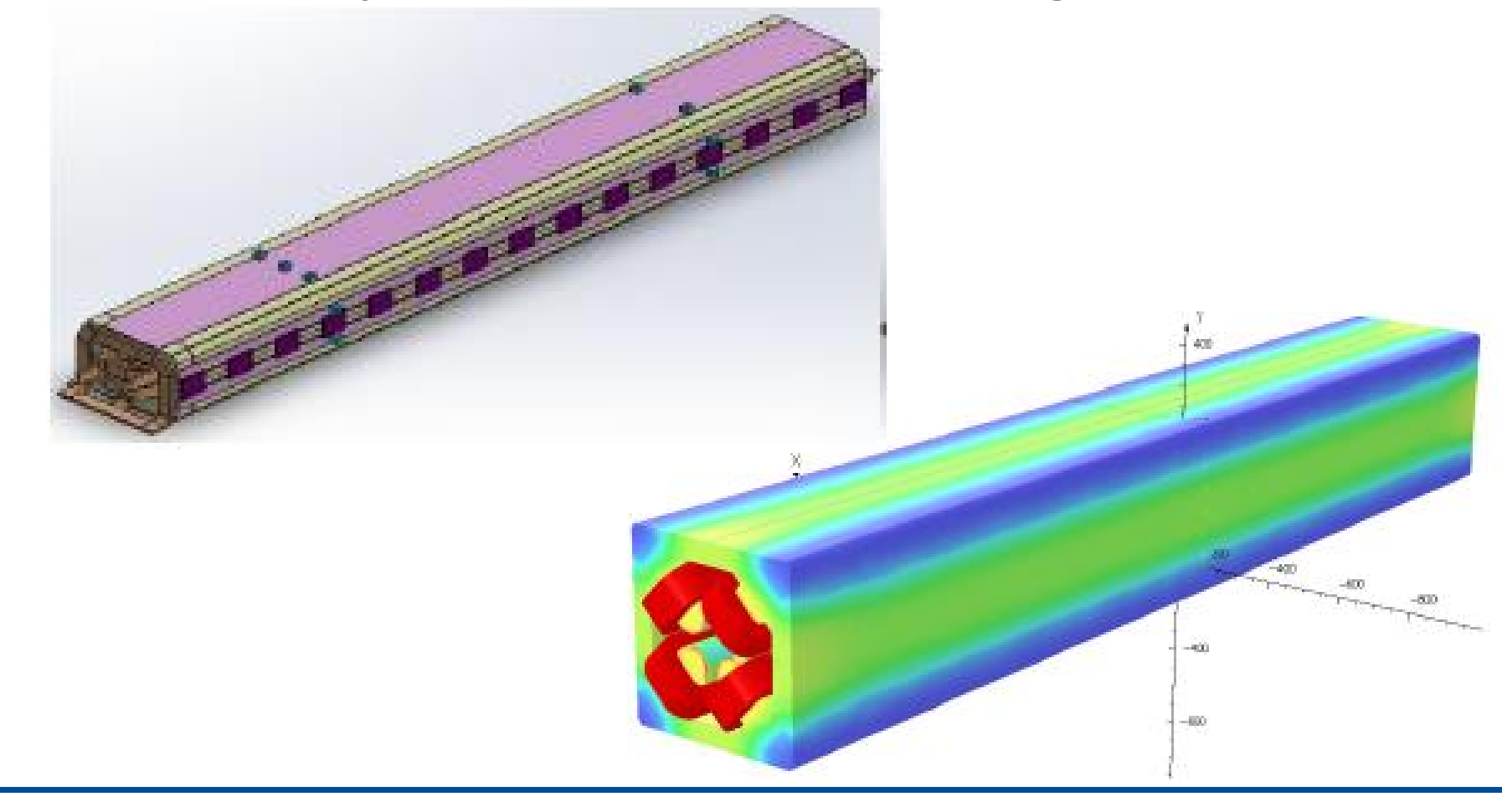

- Correctors

- IHEP of China

- Developed, produced, \& delivered

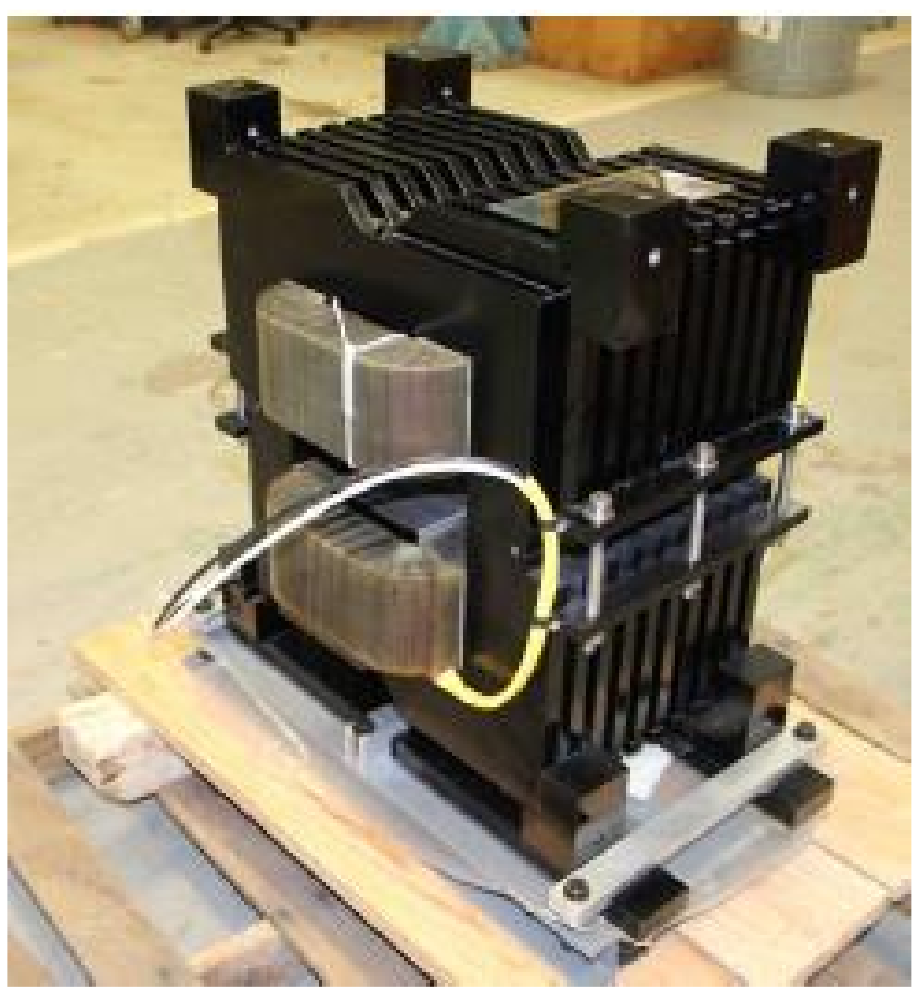




\section{Target Complex: Target Hall and Chase}

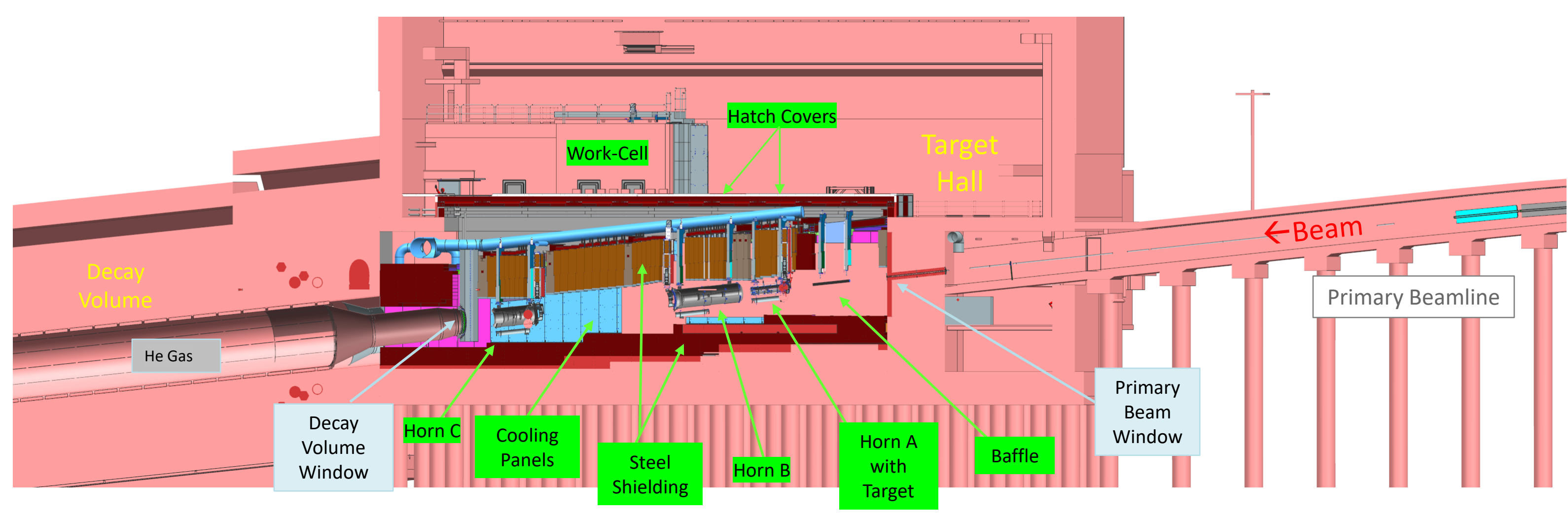




\section{Scope in Target Complex - Support Rooms}
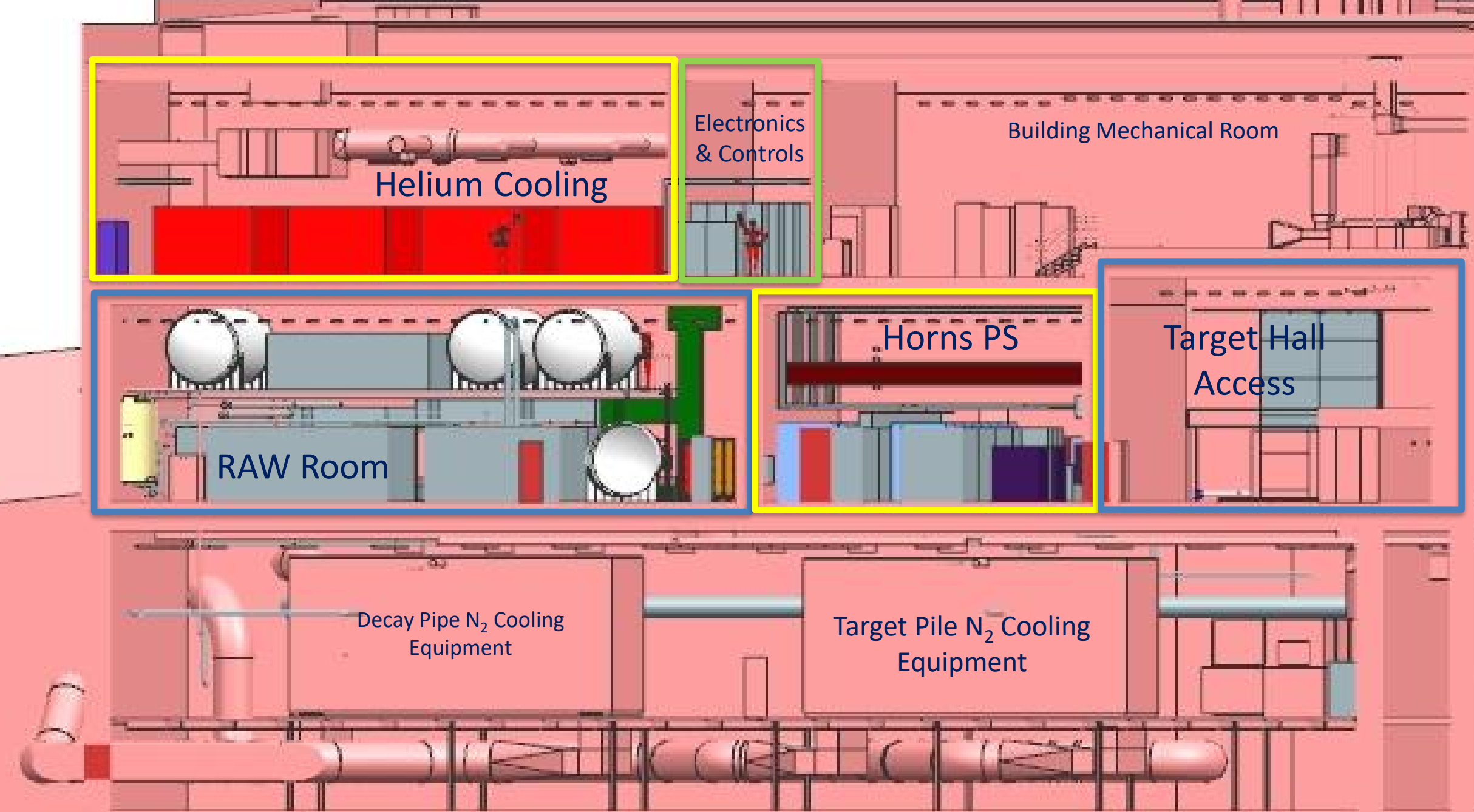

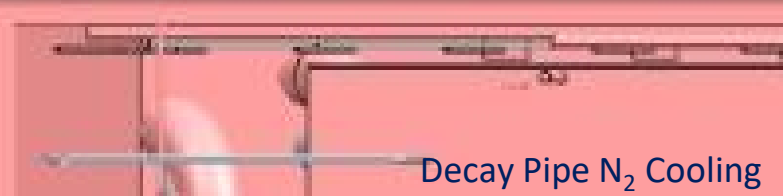

Equipment

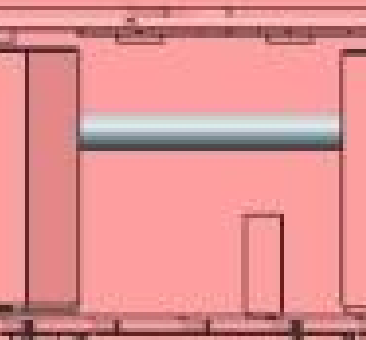

Target Pile $\mathrm{N}_{2}$ Cooling Equipment

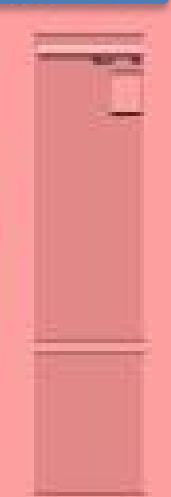

\section{|}




\section{Target}

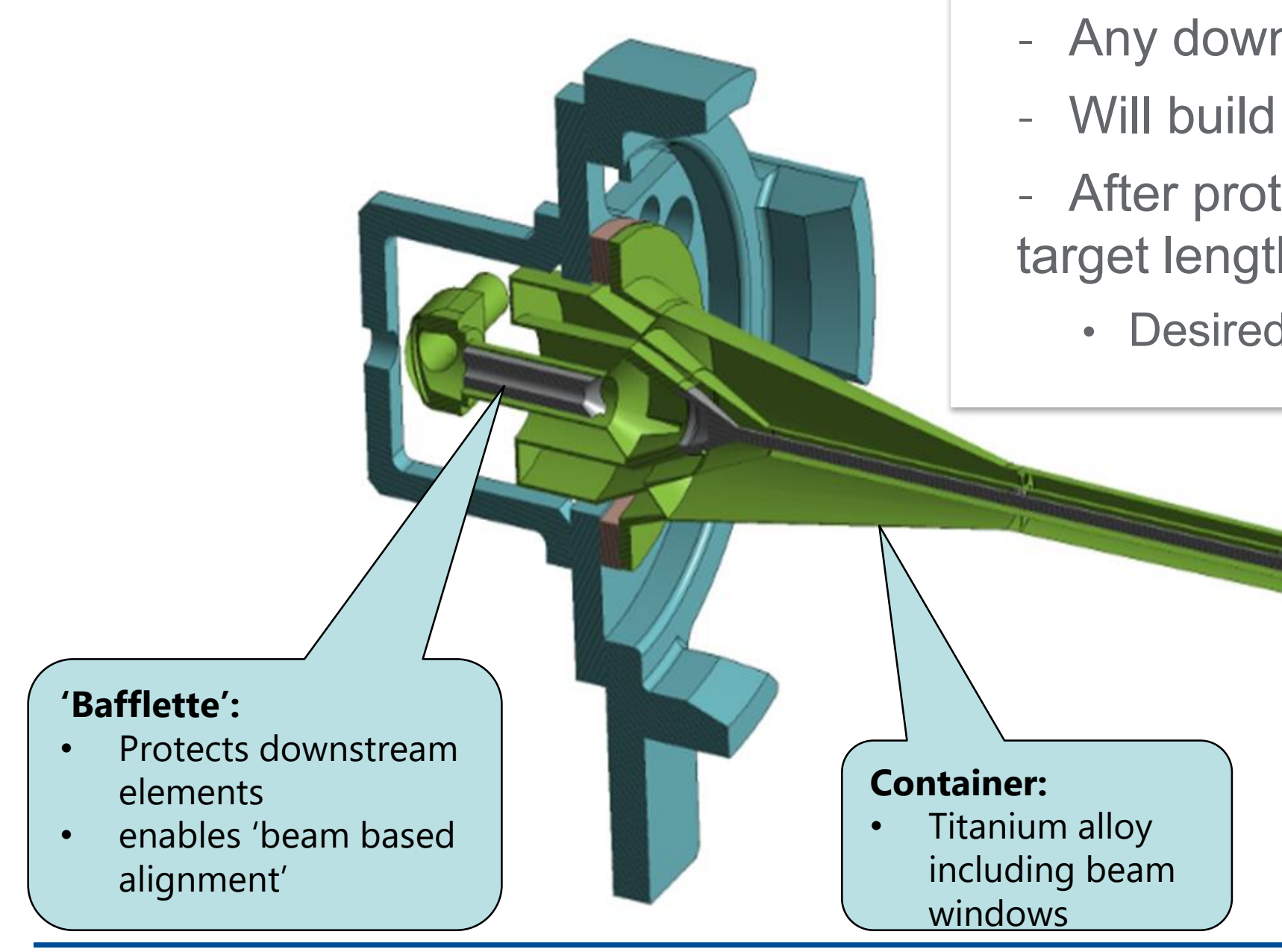

- Settled upon using a cantilevered target based upon previous work (T2K)

- Any downstream support absorbs too much

- Will build prototype of $1.5 \mathrm{~m}$ length (50\% longer than T2K) After prototype build and testing, will decided production arget length

- Desired to be $1.8 \mathrm{~m}$ to achieve four interaction lengths

\section{Container:} including beam indows

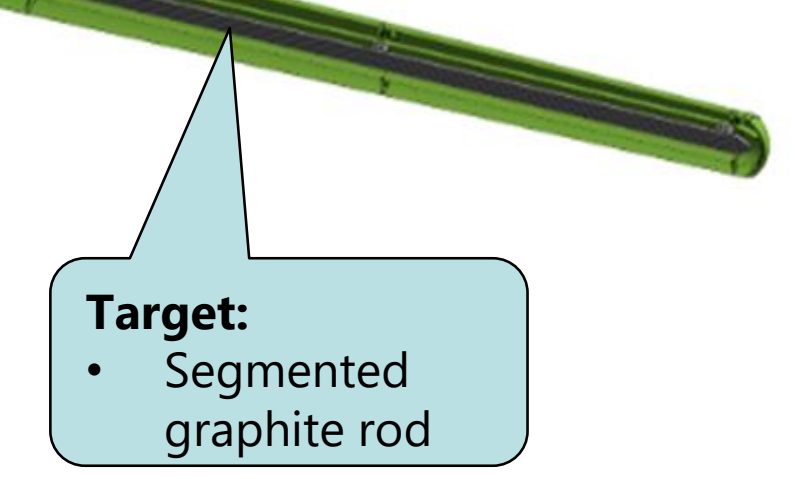




\section{Prototyping Helium Cooling Gas Manifold - Manufacturability}

cold helium in

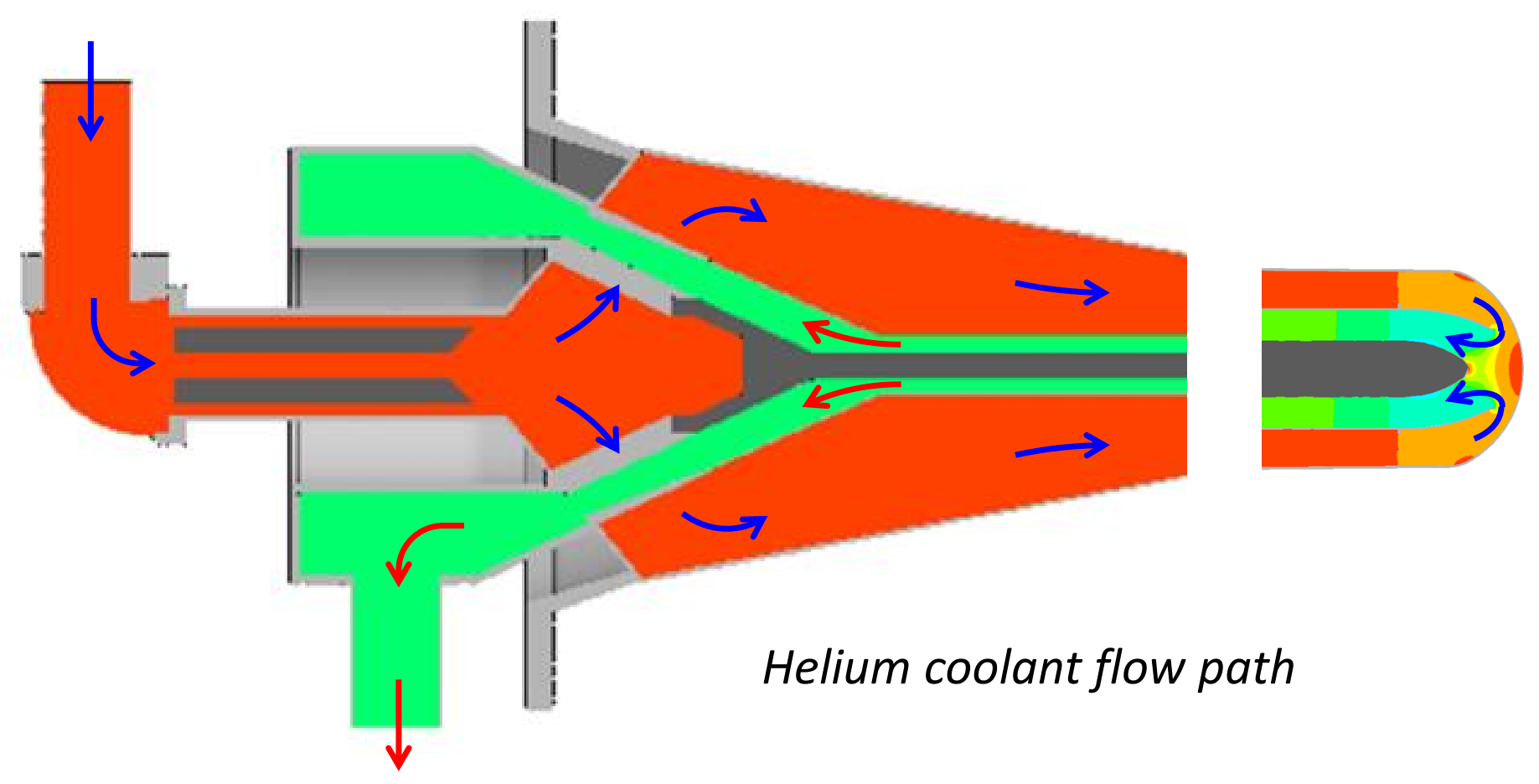

hot helium out

UKRI is moving forward with other prototyping before building a $1.5 \mathrm{~m}$ prototype $\mathrm{T}=$ target

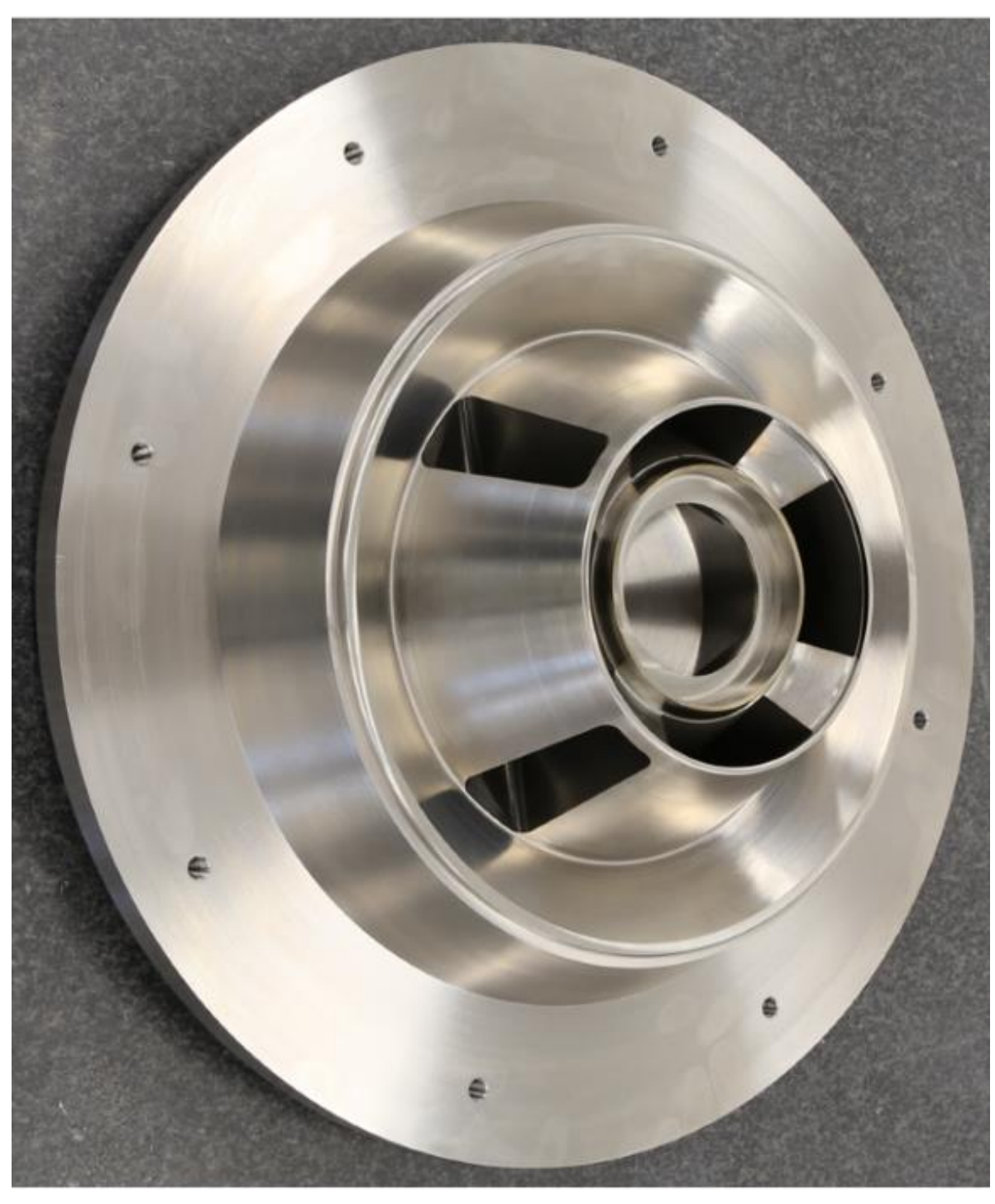




\section{Focusing Horns}

\section{Have started building a Horn A Prototype}

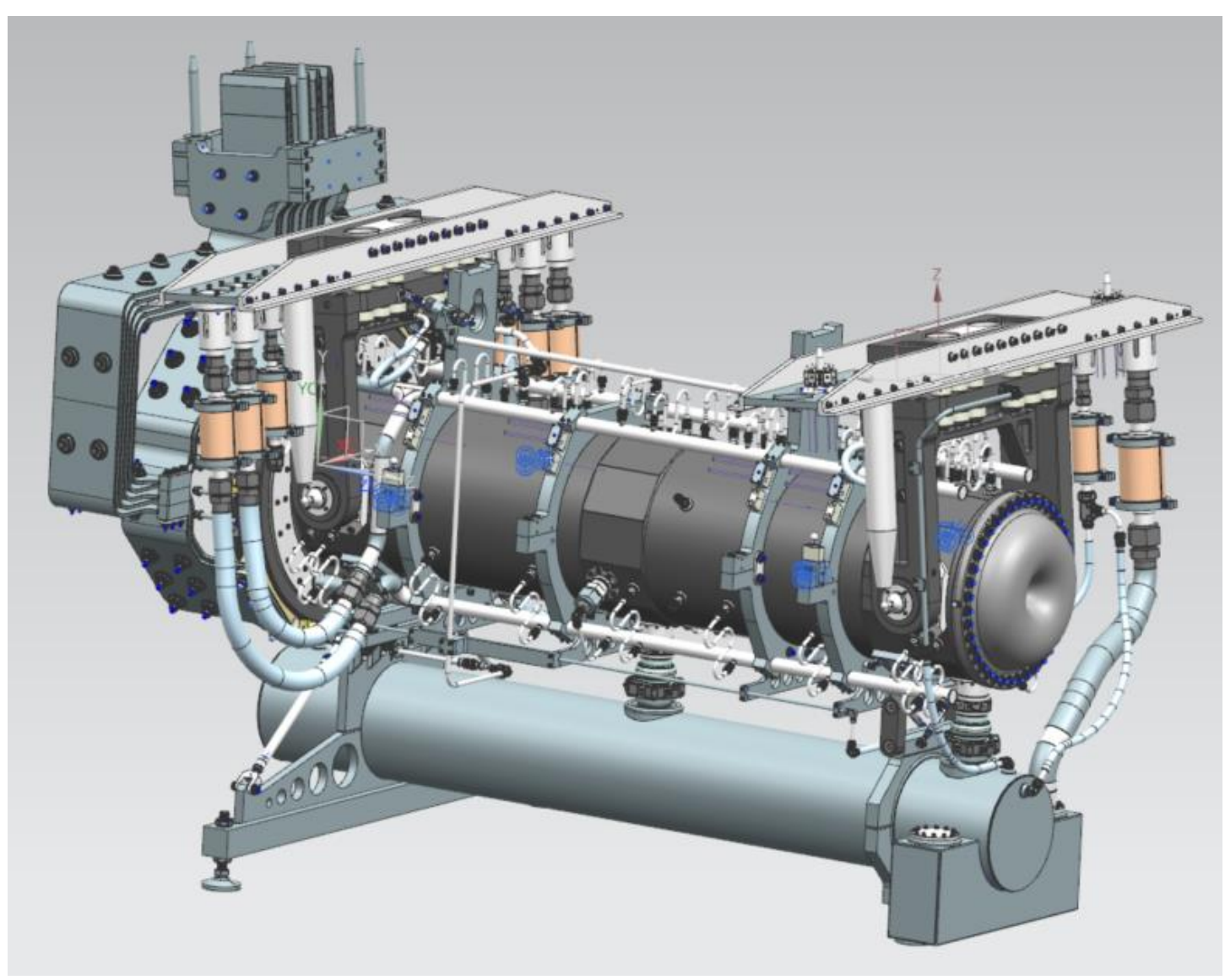

Horn A

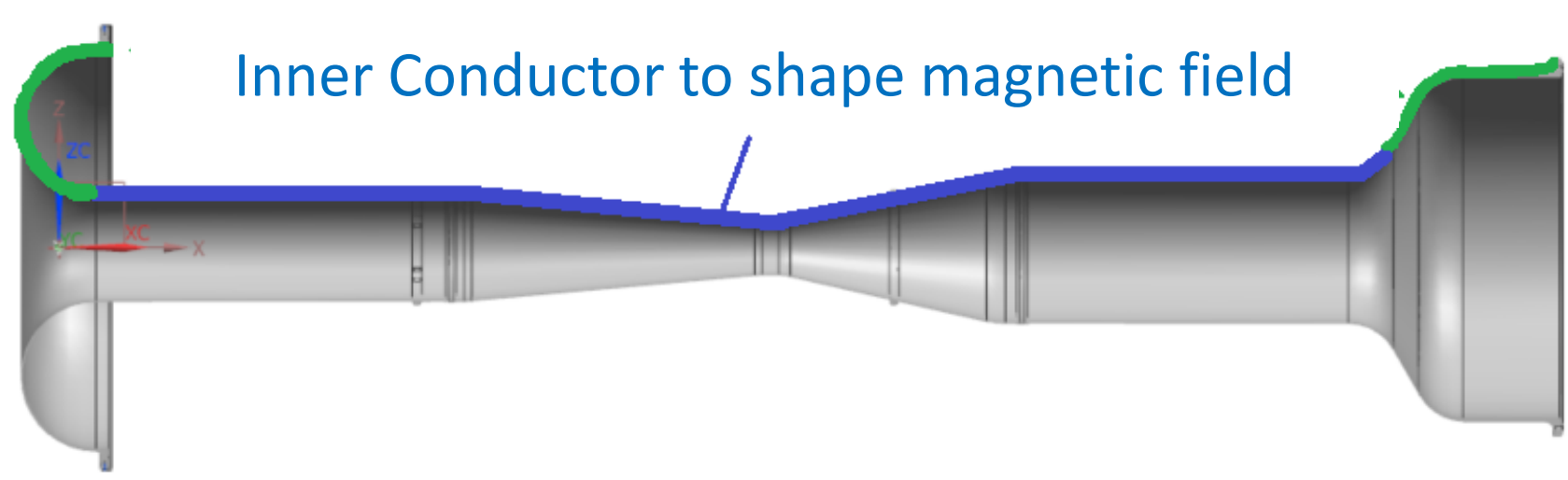

Horn B 
Integration of Target into Horn A

\author{
Green target \\ module flange \\ mates directly to \\ red pre-aligned \\ mounting plate \\ on the horn.
}

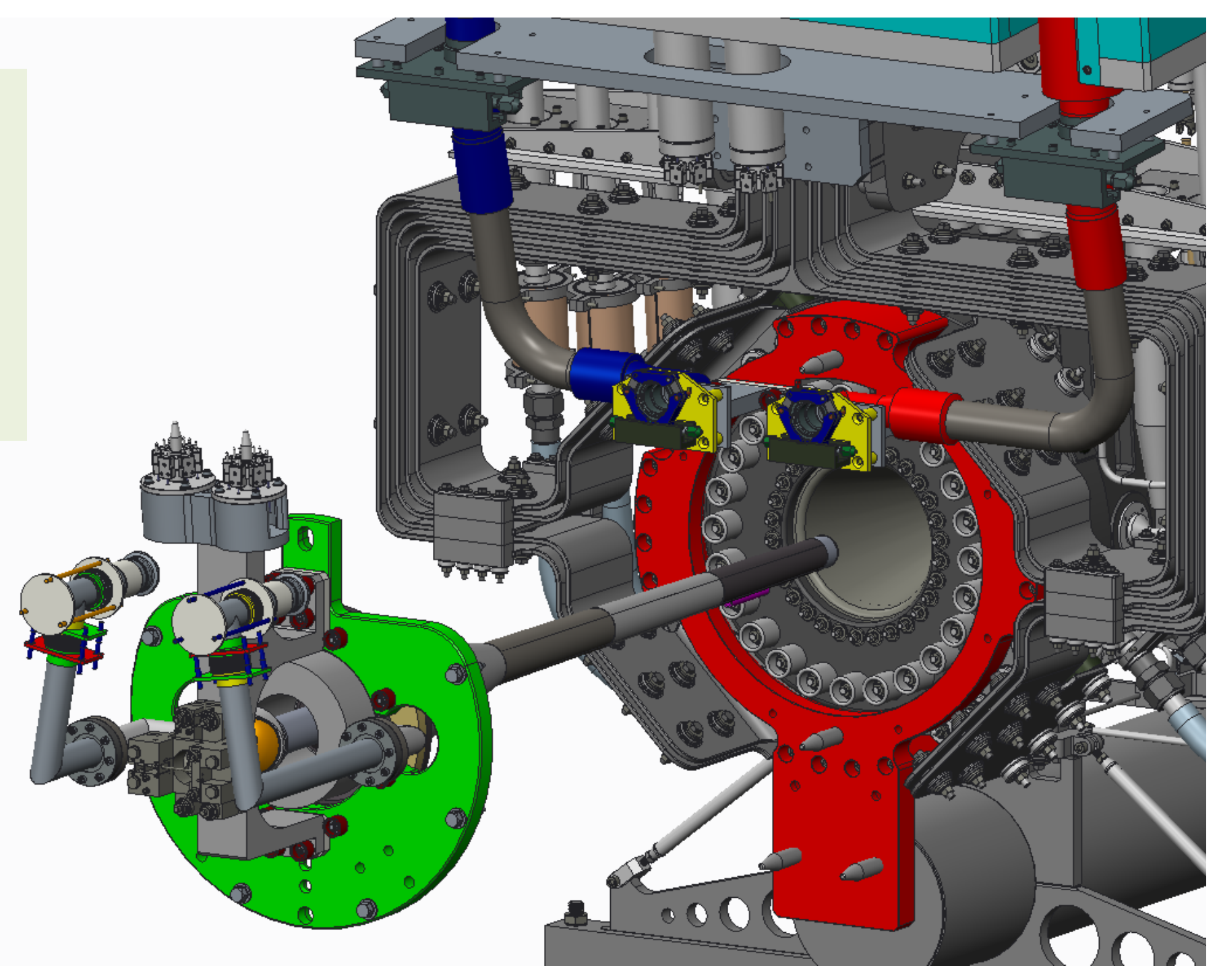




\section{Specialized Equipment to remove and install target assembly remotely}
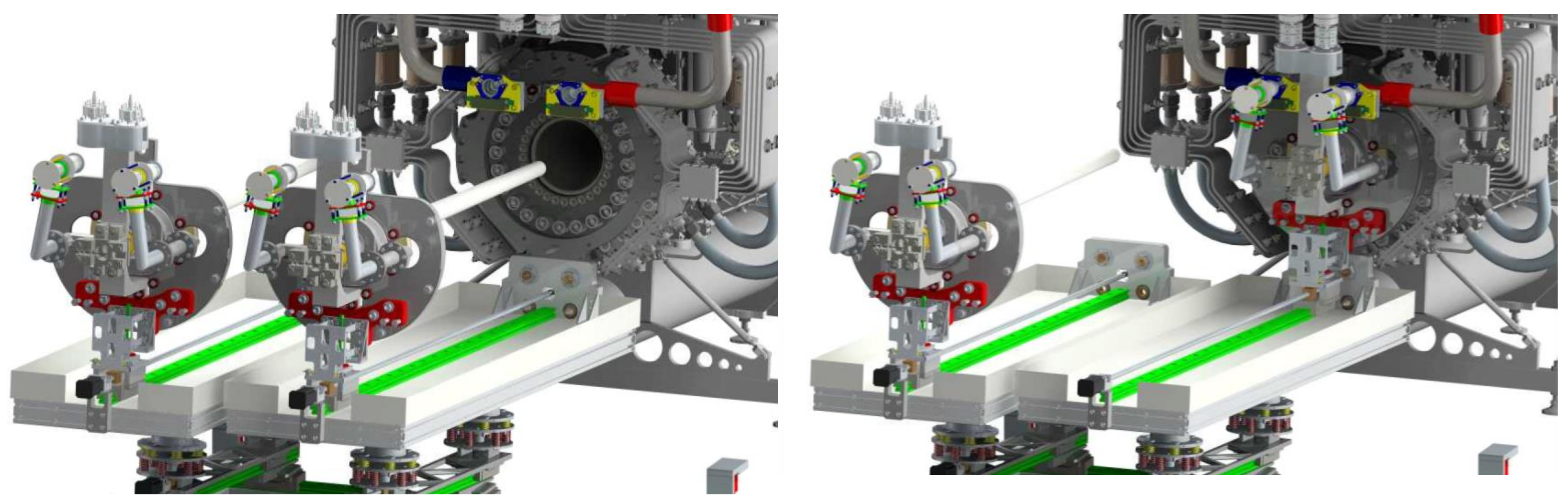

Need to remove/insert target without touching inner conductor, attach to flanges, connection of gas cooling line, $\&$ connection of instrumentation lines 


\section{Support Structure}

- Securely holds component

- Allows positioning component precisely

- Provide pathway for utilities

- Stripline bus (300,000 A)

- Cooling

- Water cooling for horn

- Helium cooling for target

- Thermocouple instrumentation

- Wall are part of radiation shielding

- Other shielding fill in

- Connections are all done via Remote Handling

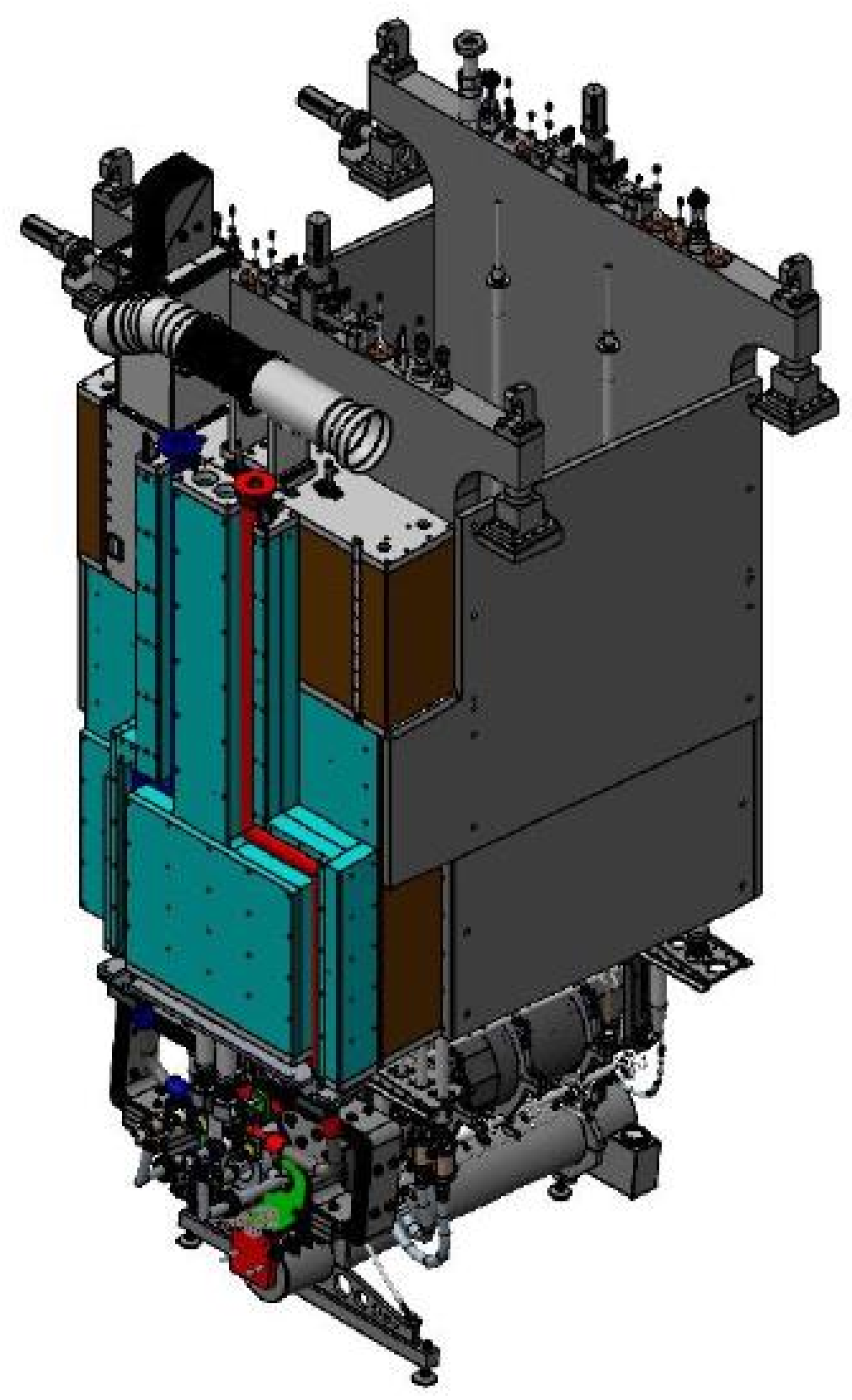




\section{Remote Handling in Work Cell}

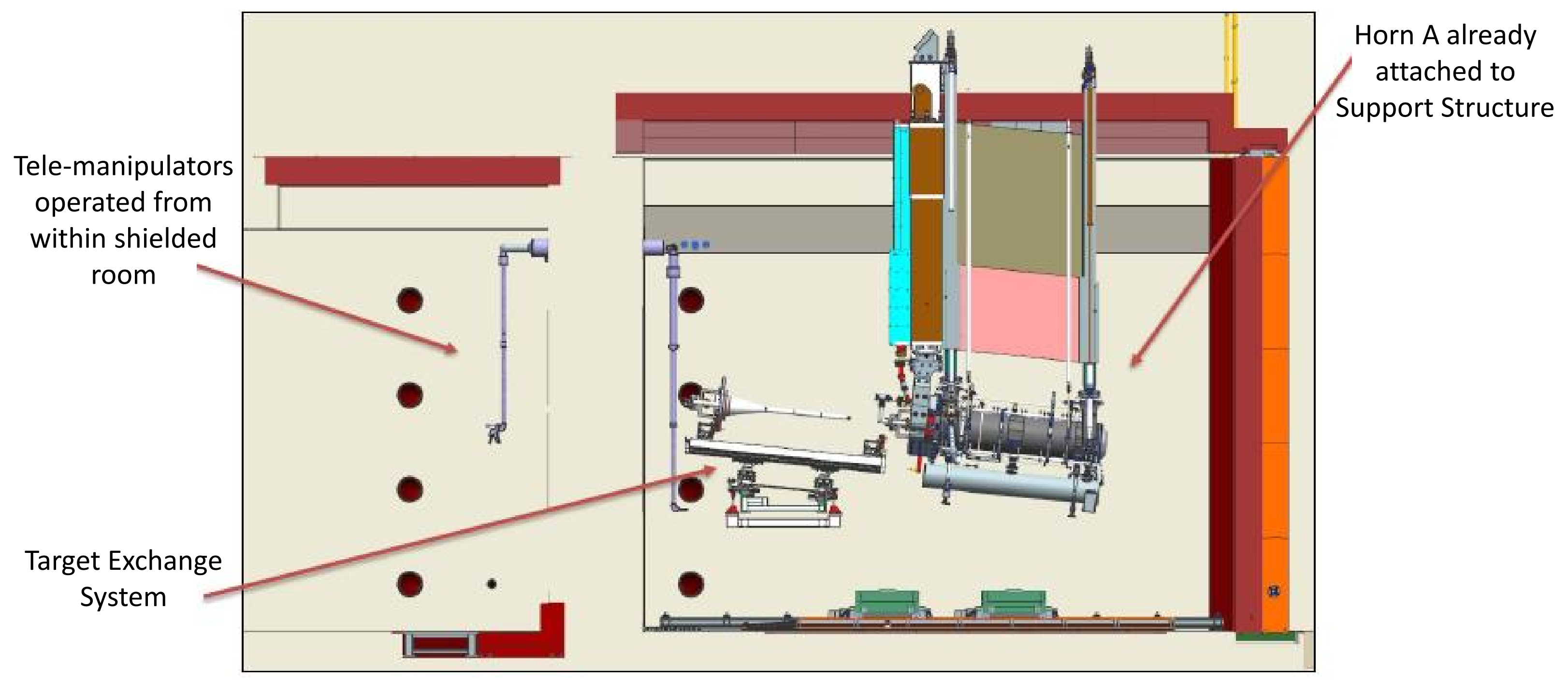


Other Recent Prototyping work
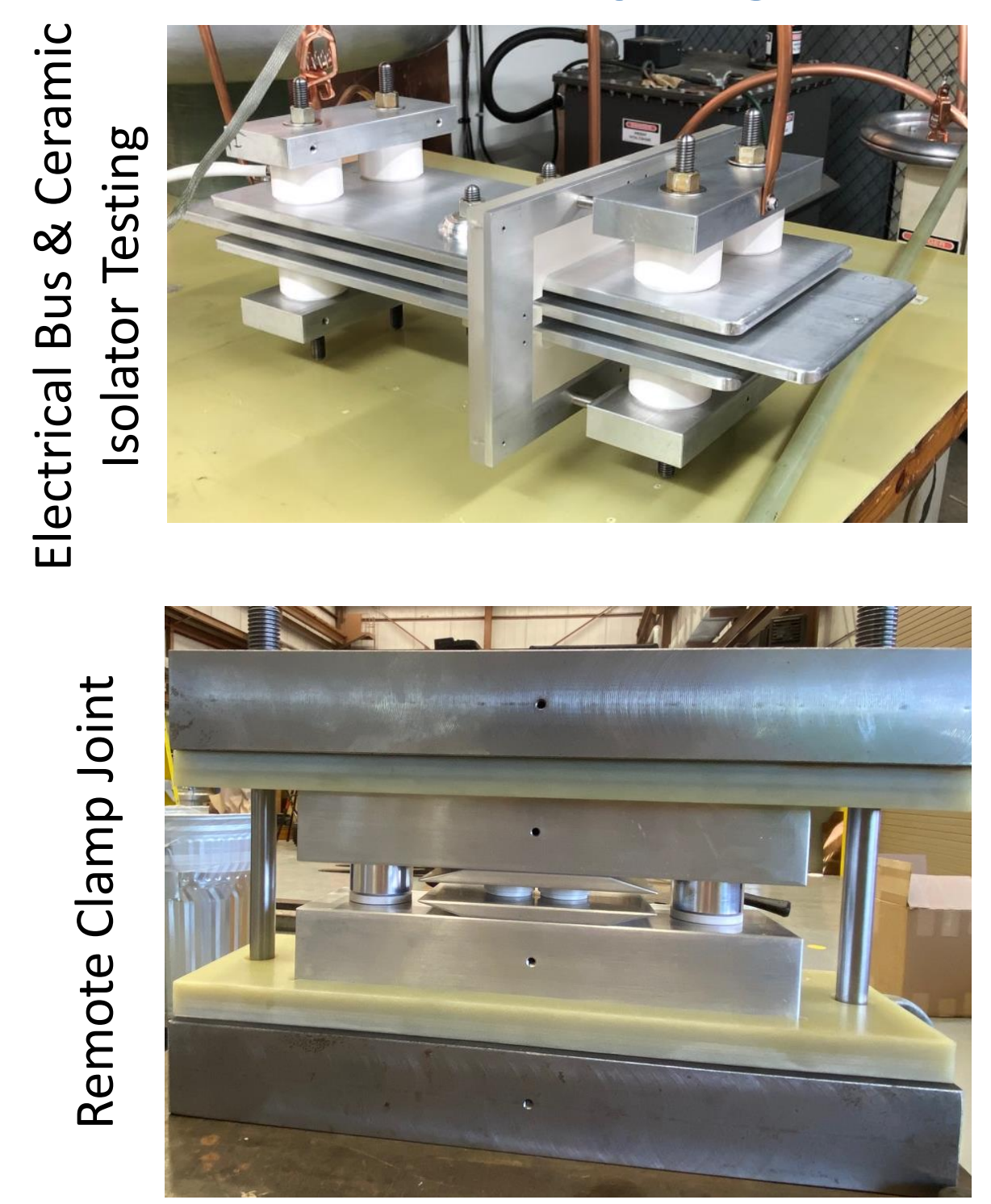

Ejection lines draw water $\sim 8.2$ meters
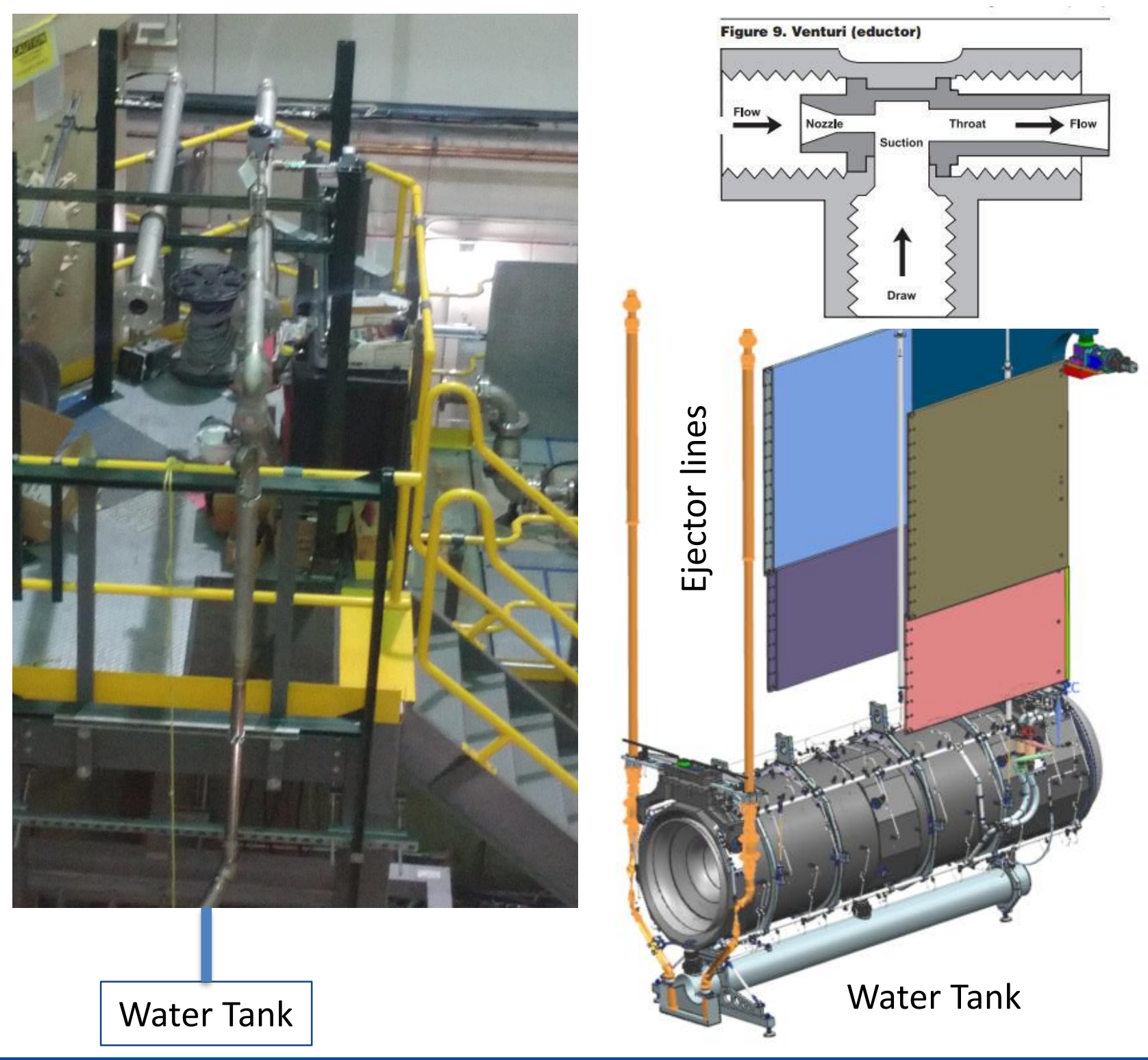

LBNF/DUNE 


\section{Decay Volume}

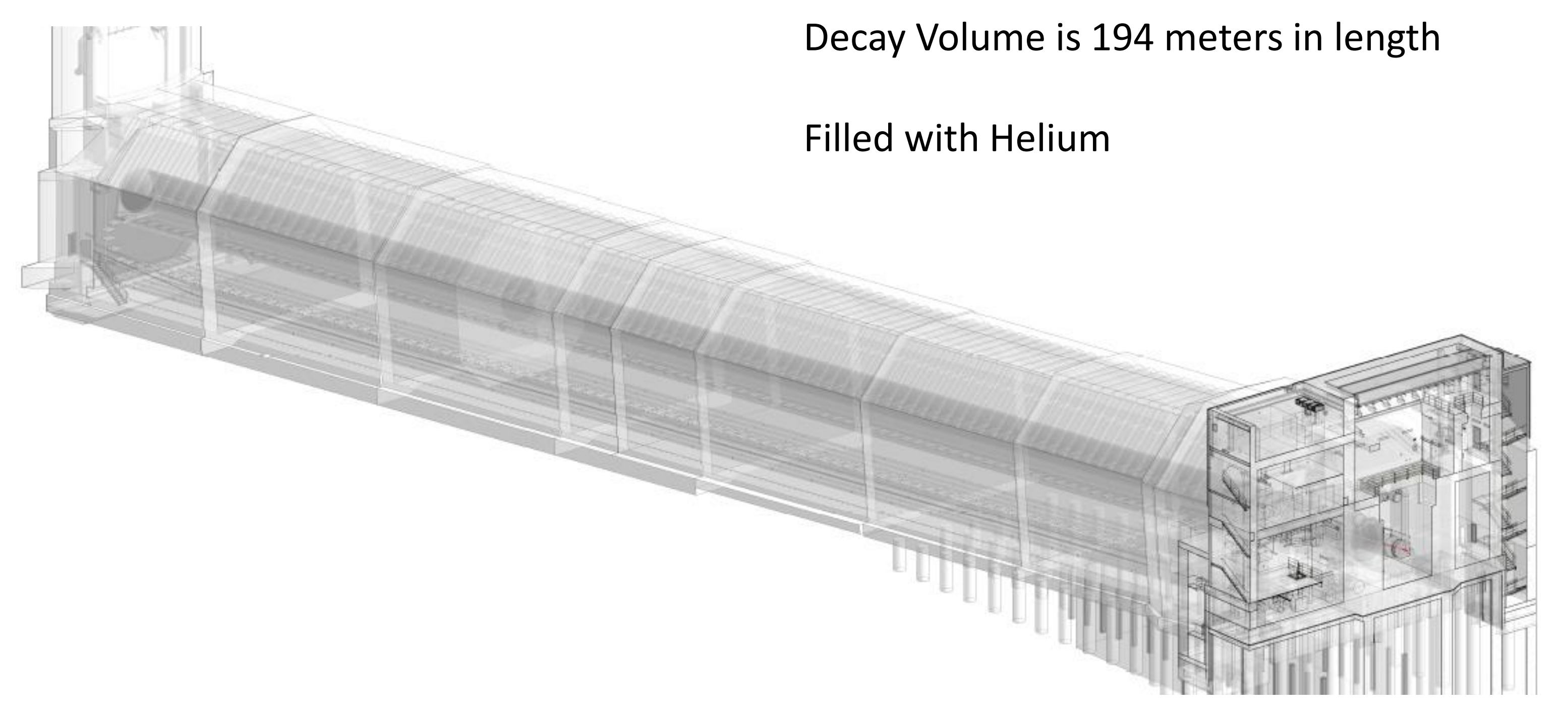




\section{Decay Volume - Typical Cross Section}

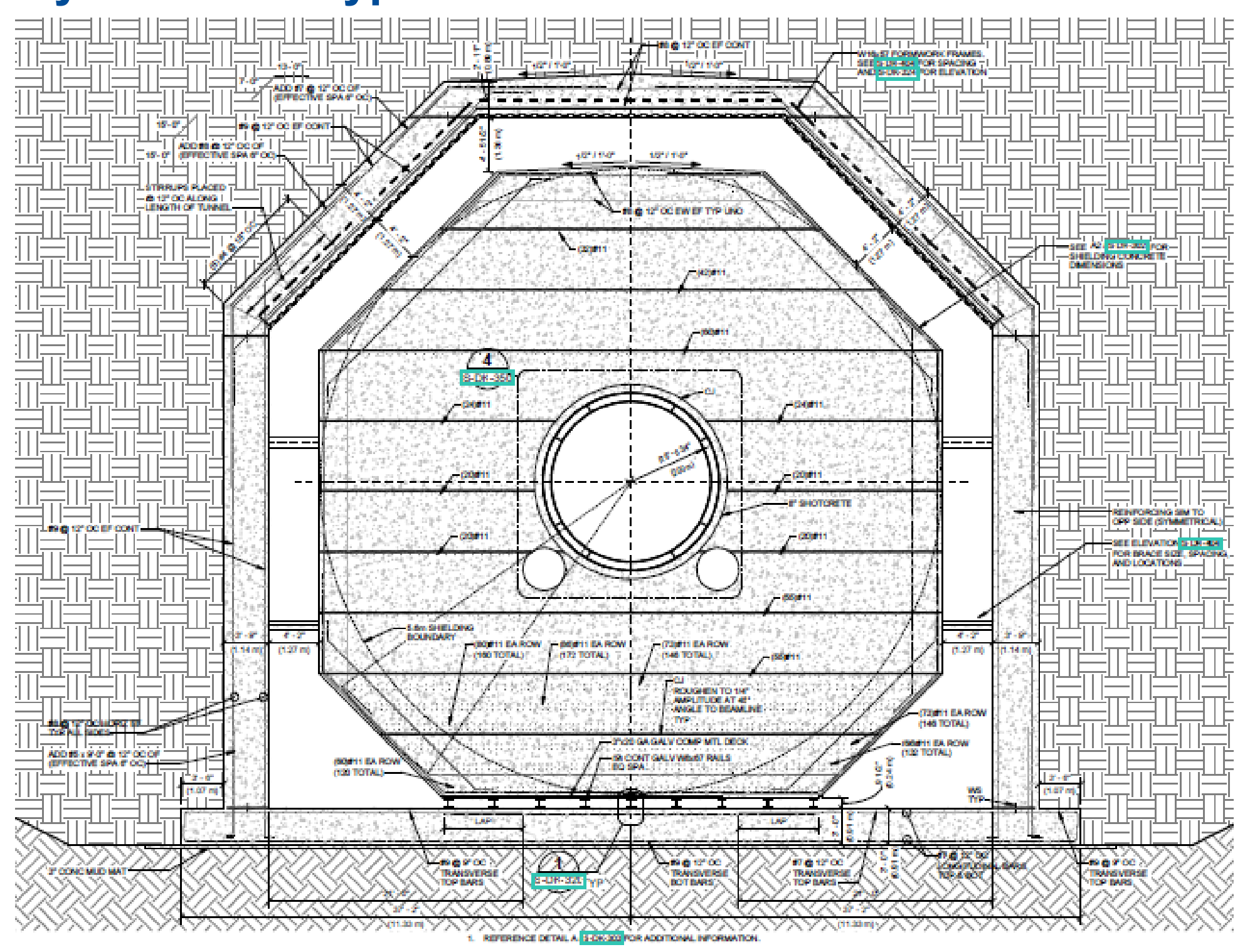

Decay Volume radius is 2.0 meters

Two concentric steel tubes

separate the helium volume from the shielding.

Surrounded by $>5.6$ meters of concrete shielding.

Cooling of the steel tubes is by nitrogen gas 


\section{Absorber Complex}

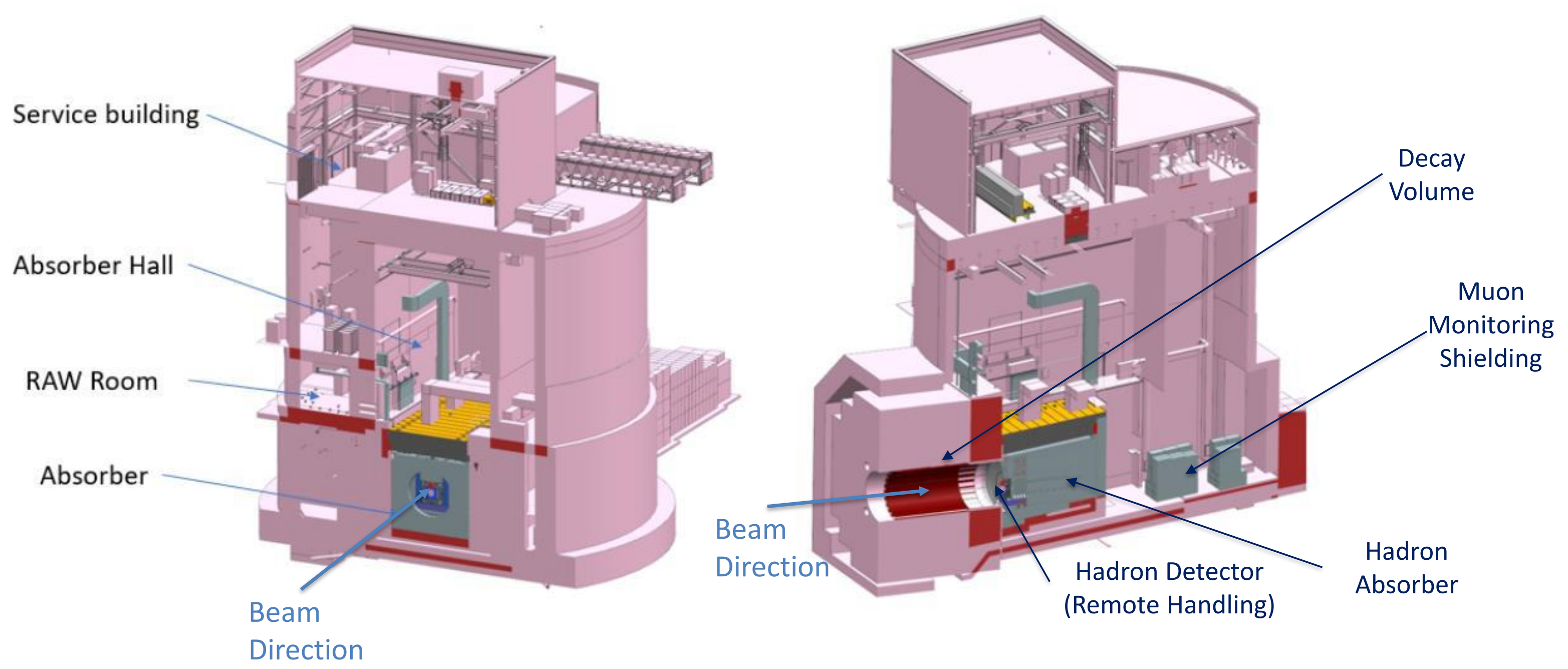

Absorber Hall Floor is $\mathbf{2 5}$ meters below ground 


\section{Hadron Detector in front of absorber}

- Used for Beam Based Alignment

- Able to lower into position when needed

- Replaceable

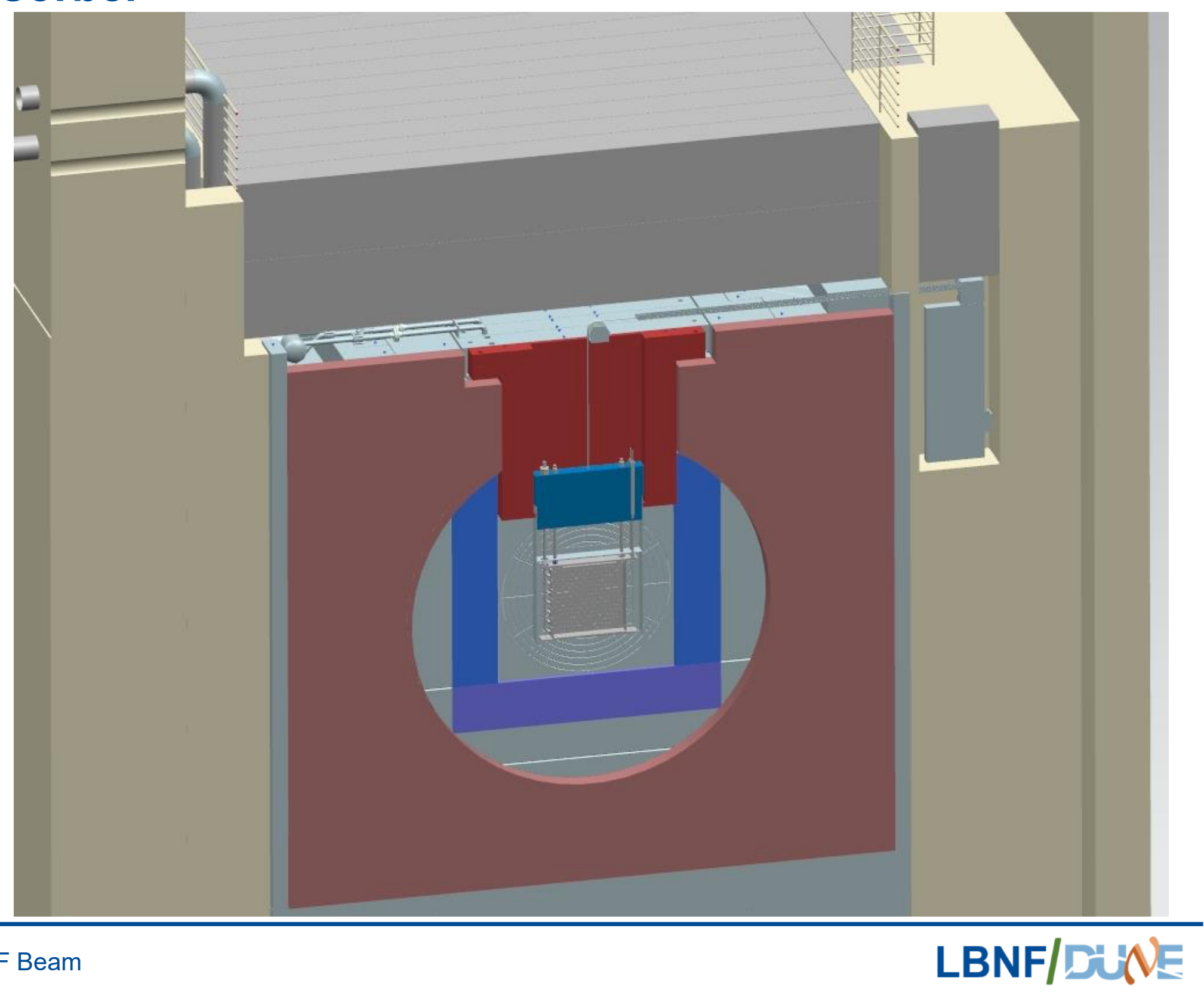


Absorber is a series of Aluminum and Steel Panels

- Water cooled

- Drilling pattern shown

- Plug/weld 16 holes

- Replaceable panels

- Designed for 2.4 MW

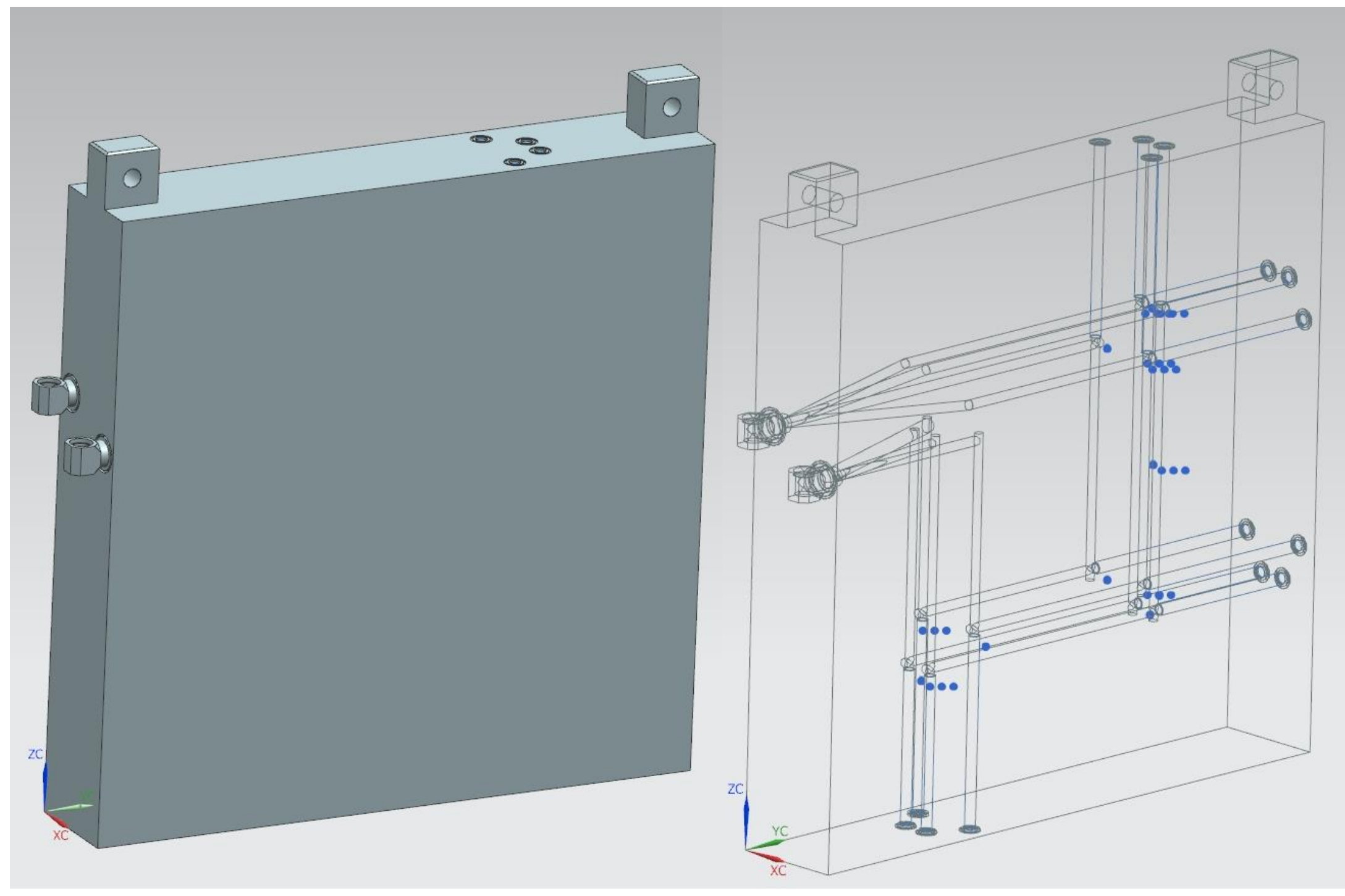




\section{Facility Instrumentation and Monitoring}

- Three muon stations behind absorber

- Samples high energy muons that are produced

- Look for changes in muon distributions

- Determine muons produced per proton on target

- Thermocouple array distributed through absorber

- Able to monitor protons not interacting with the target
- Hydrostatic Level System

- Monitor movement of Target Station components with respect to final focusing elements of proton beamline

- Vertical movements of components due to motors and thermal expansion

- Beam Based Alignment System

- Includes features on Horns, Target, \& baffle to scan beam across

- Includes retractable beam loss monitors in target chase area 


\section{Civil facilities}

- Intense design work over the last year

- Concentration on radiological issues

- Building has permanent shielding

- Control of radioactive gases

- Defining air flow path to allow isotopes to decay before release to atmosphere

- Provide a buffer volume between the radioactive air path and the atmosphere

- Control of water and ability to test water before directing to outside or to be captured

- Water seepage into facilities

- Condensate from air handling units 


\section{What is for 1.2 MW and 2.4 MW}

- What is design for 1.2 MW and could be replaced with a future upgrade

- Baffle

- Target

- Horns

- Beam windows of Target chase

- Instrumentation/Detectors

- Some cooling Systems
- What is designed for 2.4 MW and should not have to be replaced

- Proton beamline components

- All shielding

- Piping for cooling systems between support rooms and components

- Decay Volume

- Absorber

- Power Supply 


\section{Final Remarks}

- LBNF Beamline is part of the LBNF/DUNE-US Project

- The LBNF Beamline is based upon the experiences of other neutrino beamlines

- Prototyping is in progress

- Facility will support initial beam power of $1.2 \mathrm{MW}$ and is upgradeable to $2.4 \mathrm{MW}$ 